\title{
Risk factors for cost-related medication non-adherence among older patients with cancer
}

\author{
James X. Zhang ${ }^{1 *}$ and David O. Meltzer ${ }^{1-3}$ \\ ${ }^{1}$ Section of Hospital Medicine, Department of Medicine, The University of Chicago, USA \\ ${ }^{2}$ Department of Economics, The University of Chicago, USA \\ ${ }^{3}$ Harris School of Public Policy, The University of Chicago, USA
}

\begin{abstract}
We aimed to assess the risk factors for cost-related medication non-adherence (CRN) among older patients with cancer in the United States. We used data from the 2010 Health and Retirement Study (HRS) to assess risk factors for CRN including age, insurance coverage, nursing home residence, functional limitations, and frequency of hospitalization among old patients with cancer. CRN was self-reported. We conducted a multivariate regression analysis to assess the effect of each risk factor. 293 (9.9\%) of 2,953 older patients (50+ years) cancer patients reported CRN. Those who reported CRN were more likely to be younger, women, African American, and Hispanics. Compared to those with Medicare, those with no health insurance coverage were $97 \%$ more likely to report CRN. High number in limitation in activities of daily living and hospitalization significantly increased risk for CRN. Sicker cancer patients were more likely to report CRN. Lack of health insurance may have prevented the cancer patients from receiving optimal care. Together, these results suggest that expanding insurance coverage and improving insurance benefit design for cancer patients is likely to decrease CRN and improve outcomes.
\end{abstract}

\section{Introduction}

Access barrier to effective medication treatment has been a persistent issue for millions of older Americans. Research has shown that up to a third of older patients report cost-related medication nonadherence (CRN) [1]. Socio-economic factors such as lower income and high out-of-pocket costs for medications, and health status including lower self-perceived general health, more comorbidities, and poorer mental health are strong risk factors for CRN, while having any or more generous prescription drug coverage significantly reduces the risk of CRN [2-6]. Cancer is one of the most expensive conditions in the U.S., and lack of health insurance and other barriers prevent many Americans from receiving optimal health care [7]. Although research has suggested that patients are sensitive to the out-of-pocket payments to medications even in medications used to treat cancer [8], a comprehensive framework of risk factors for CRN in cancer patients is lacking.

There is an increasing recognition of the importance of CRN in cancer patients. Lower income, minority status, and lack of health insurance have been identified as risk factors for CRN, and there is a persistent gender difference in CRN among cancer survivors $[9,10]$. In these patients, medication non-adherence can significantly reduce the effectiveness of care, placing them at an increased risk of declining health and incurring significant downstream costs. However, little is known about the other factors associated with CRN in cancer patients, particularly metrics of the high burden of disease, including limitations in functional status, frequency of hospitalization, residence in a nursing home, and comparative risk among various public and private health insurance plans. Several of these risk factors can be potentially modified through changes in social policy and clinical practice, but a better understanding of these factors is necessary to inform these changes. In this study, our aim was to assess variation in CRN with a broad set of risk factors for cancer patients over the age of 50 using a nationally representative dataset.

\section{Research design and methods}

\section{Study population}

We utilized the 2010 data from the Health and Retirement Study (HRS). The HRS is an ongoing longitudinal cross-sectional study that surveys a nationally representative sample of Americans over the age of 50 about their income, employment, health insurance, physical health, cognitive functioning, and health care expenditures [11]. Data for the survey are collected primarily by telephone interview every two years. The analysis in this study was restricted to survey respondents who reported previously diagnosed cancer or a malignant tumor, excluding minor skin cancer.

\section{Cost-related medication non-adherence}

CRN was measured by asking participants, "Sometimes people delay taking medication or filling prescriptions because of the cost. At any time since the last interview or in the last two years have you ended up taking less medication than was prescribed for you because of the cost?" Participants answered either "yes" or "no," although they had the option to refuse to answer or say that they did not know.

Correspondence to: James X. Zhang, $\mathrm{PhD}$, MS, Section of Hospital Medicine, Department of Medicine, 5841 S. Maryland Ave., MC 5000, Chicago, IL, 60637, USA; E-mail: xzhang1@medicine.bsd.uchicago.edu

Key words: medication adherence, risk factors

Received: October 16, 2015; Accepted: November 03, 2015; Published: November 06, 2015 


\section{Demographic and socio-economic characteristics}

The HRS includes questions about demographics and socioeconomic characteristics, including age, place of birth, education level, ethnicity, employment, and place of residence. We categorized patients into insurance groups of Medicare only, Medicaid only, Medicare and Medicaid dual eligible, private insurance, and no health insurance. We hypothesized that patients in the no-insurance group are at elevated risk of CRN because they do not have insurance coverage and have a high burden of out-of-pocket payments, while those patients with Medicare or dual eligibility may behave differently from those with Medicare only due to lower income and higher disease burden. We also included a variable indicating residence in a nursing home, hypothesizing that living in a nursing home would decrease the risk of CRN due to administration of medications by the nursing staff. Nursing home patients were also more likely to qualify for Medicaid due to low income, and thus out-of-pocket payments for medications should also be reduced, further decreasing the risk of CRN [12].

\section{Functional status and number of hospitalizations}

HRS asks participants about functional status through questions on limitations in activities of daily living (ADLs) and instrumental activities of daily living (IADLs) [13,14], with higher numbers of limitations indicating worse functional status. Functional limitations may reflect the effects of underlying diseases such as advanced cancer or other chronic diseases, and can act as barriers to purchasing and administering medications as prescribed [12].

The HRS also collects information about healthcare utilization, including hospitalizations and physician visits. Participants were asked the number of different times they were hospitalized overnight in the past two years, as well as how many nights they stayed. We hypothesized that controlling for other socioeconomic factors, including insurance, the number of hospitalizations better predicts the underlying disease burden and may reveal the adequacy of insurance coverage, even if the cancer patients have Medicare, Medicaid, or both. Therefore, higher frequencies of hospitalization should be associated with higher risk of CRN [12]

\section{Statistical analysis}

We first performed bivariate analyses of the association between CRN and socio-demographic variables, limitations in ADLs and IADLs, number of hospitalizations, and type of insurance coverage. We examined differences in CRN for varying levels of limitations in ADLs and IADLs, hospitalizations, insurance coverage and sociodemographic variables by utilizing chi-square statistics.

We then conducted multivariate regression analysis to assess the net effects of the aforementioned risk factors on CRN. In this case, a logit model was used to assess the independent risk factors including age, nursing home residence, health insurance coverage, varying level of limitations in ADLs and IADLs, and number ofhospitalizations.

\section{Results}

Among the 22,042 respondents in the 2010 HRS, 2,992 (13\%) reported that they had been previously diagnosed with cancer or a malignant tumor, excluding minor skin cancer. Among those 2,992 cancer patients, 293 reported CRN in the past two years, while 29 refused or did not know if they had taken less medication due to costs. Excluding those 29 patients fromsubsequent analysis resulted in a final sample size of 2,953 . The mean age of the 2,953 cancer patients was 72 years (s.d. 11), with a minimum of 50 and maximum of 101 years.
Table 1 shows the prevalence of CRN by different sociodemographic variables. Those who reported CRN were more likely to be younger, female, African-Americans, and Hispanic. Those who reported CRN were also more likely not having any type of insurance coverage, or with Medicaid.

Figure 1 shows the association between the number of limitation in ADLs and the percentage of patients who reported CRN. As number of ADL limitation increased, the CRN rate also increased $(\mathrm{p}<0.01)$. A similar pattern was shown in Figure 2 between the number of hospitalization and the percentage of patients who reported CRN $(\mathrm{p}<0.01)$. For IADL, those who had 1 or more IADL limitation were more likely to report CRN $(\mathrm{p}<0.01)$, but the rates were narrowly in a range of $12-14 \%$ for those with $1,2,3$ or more IADL limitations.

Table 2 shows the independent risk factors of CRN in the multivariate logistic regression model. The likelihood of CRN decreased as patient age advanced. When using Medicare as reference group, those with Medicaid or dual eligibility were not statistically significantly different in CRN rates, while those without any type of insurance were $97 \%$ more likely to report CRN. Compared to those without any limitations, survey respondents with 1, 2, 3 or more limitations in ADLs were $62 \%$, $126 \%$, and $135 \%$ more likely to report CRN, respectively. Compared to those without any hospitalizations, those who had 1, 2, 3 or more hospitalizations were $42 \%, 63 \%$, and $102 \%$ more likely to report CRN, respectively.

\section{Discussion}

We found that there were about $9.9 \%$ of cancer patients reported $\mathrm{CRN}$, and those who reported CRN were more likely to be female, African American,or Hispanic. These results reflected that a significant proportion of cancer patients were constrained by the economic burden of medical care, and have to cut medication to avoid costs, which may render the medical treatment less effective, and increase the overall costs of treatment to the society.

We also found that those who did not have any type of public or private insurance were significantly more likely to report CRN. The negative association between age and CRN rate corroborates this finding that those who do not have a group insurance policy and are younger than 65 (and thus not eligible for Medicare), were at high risk for CRN. The cost to buy a private insurance policy was prohibitively expensive for cancer patients, if they were not poor enough to be eligible for Medicaid before they reach the age to be eligible for Medicare. The Affordable Care Act (i.e., Obamacare) has expanded Medicaid coverage to those at $138 \%$ federal poverty level. However, 22 states did not expand Medicaid and these states are more likely to have very limited Medicaid eligibility [15]. Efforts are much needed to alleviate the economic burden of cancer patients in these states who could not afford private health insurance.

We also found that sicker cancer patients with higher number of functional limitations and hospitalizations were much more likely to report CRN. This suggested that even for those with Medicare, Medicaid or dual eligibility, the current health insurance coverage were not adequate for those high-need, high-cost patients. Total medical costs were driven by a small fraction of patients and highly concentrated [16], and higher CRN rate in sicker cancer patients may further drive up the concentration of spending, and constrain the resources available for other uses. Improvement in insurance benefit design, such as reducing out-of-pocket payment based upon the value of treatment, is needed to improve the access to care for the very sick 
Table 1. Prevalence of CRN by socio-demographics and insurance status.

\begin{tabular}{|c|c|c|c|c|}
\hline & All & $\begin{array}{c}\text { Reported CRN } \\
\text { N (\%) }\end{array}$ & $\begin{array}{c}\text { Did Not Report CRN } \\
\text { N (\%) }\end{array}$ & P-value \\
\hline Full sample: N (\%) & $2,953(100)$ & $293(100)$ & $1,231(100)$ & \\
\hline \multicolumn{4}{|l|}{ Age } & \multirow{2}{*}{$<0.01$} \\
\hline Mean (s.d.) & $72(11)$ & $65(10)$ & $73(10)$ & \\
\hline \multicolumn{4}{|l|}{ Gender } & \multirow{3}{*}{$<0.01$} \\
\hline Male & $1,318(45)$ & $87(30)$ & $1,231(46)$ & \\
\hline Female & $1,635(55)$ & $206(70)$ & $1,429(54)$ & \\
\hline \multicolumn{4}{|l|}{ Race } & \\
\hline White & $2,433(83)$ & $218(74)$ & $2,225(84)$ & \multirow{3}{*}{$<0.01$} \\
\hline African-American & $432(14)$ & $63(22)$ & $360(14)$ & \\
\hline Other & $87(3)$ & $12(4)$ & $73(3)$ & \\
\hline \multicolumn{4}{|l|}{ Ethnicity } & \multirow{3}{*}{0.04} \\
\hline Hispanic & $109(4)$ & $17(6)$ & $92(3)$ & \\
\hline Non-Hispanic & $2,844(96)$ & $276(94)$ & $2,568(97)$ & \\
\hline \multicolumn{4}{|l|}{ Nursing home residence } & \multirow{3}{*}{0.25} \\
\hline Living in NH: N (\%) & $81(3)$ & $5(2)$ & $76(3)$ & \\
\hline Not in NH: N (\%) & $2,872(97)$ & $288(98)$ & 2,584 (97) & \\
\hline \multicolumn{4}{|l|}{ Insurance coverage } & \\
\hline \multicolumn{4}{|l|}{ Medicare coverage } & \multirow{3}{*}{$<0.01$} \\
\hline Current covered: N (\%) & $2,238(76)$ & $180(61)$ & $2,058(77)$ & \\
\hline Not covered: N (\%) & $715(24)$ & $113(39)$ & $602(23)$ & \\
\hline \multicolumn{4}{|l|}{ Medicaid coverage } & \multirow{3}{*}{$<0.01$} \\
\hline Currently covered & $288(10)$ & $54(18)$ & $234(9)$ & \\
\hline Not covered & $2,655(90)$ & $239(82)$ & $2,426(91)$ & \\
\hline \multicolumn{4}{|l|}{ Dual eligibility } & \multirow{3}{*}{$<0.01$} \\
\hline Currently covered & $217(7)$ & $34(12)$ & $183(7)$ & \\
\hline Not covered & $2,736(93)$ & $259(88)$ & $2,477(93)$ & \\
\hline \multicolumn{4}{|l|}{ Private insurance } & \multirow{3}{*}{$<0.01$} \\
\hline Current covered & $1,634(55)$ & $116(40)$ & $1,518(57)$ & \\
\hline Not covered & $1,319(45)$ & $177(60)$ & $1,142(43)$ & \\
\hline No Insurance & $137(5)$ & $44(15)$ & $93(4)$ & \multirow[b]{2}{*}{$<0.01$} \\
\hline Any insurance & $2,816(95)$ & $249(85)$ & $2,567(97)$ & \\
\hline
\end{tabular}

P-values by Chi-squared tests, except for age, where t-test was performed

and needy patients.

We found that women were more likely to report CRN. This is consistent with the previous finding in the cancer patients and in general population $[10,17]$. It is less clear if this is in part due to that women are more price sensitive to out-of-pocket payment for medication, have different perception of the effectiveness of medication, or differential level of health literacy. Research is needed to advance the understanding the gender difference in the behavioral aspect of CRN.

This study is limited in that while we have shown that a number of factors may be affecting CRN, we do not have measures of some key factors, such as out-of-pocket payments. As a result, the exact reason for CRN among those with drug insurance coverage is less clear. The HRS survey also does not give us any indication of how often participants did not take their medications due to cost, and only asks

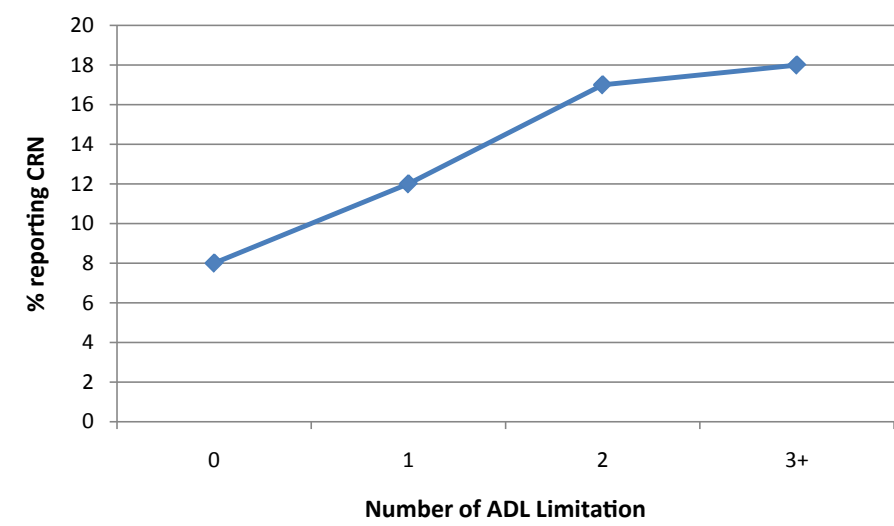

Figure 1. The association between the number of limitation in Activities of Daily Living and percentage of patients reporting $\mathrm{CRN}$. $\mathrm{p}<0.01$ by chi-square test. 
Table 2. Independent risk factors for Cost-related Medication Non-adherence.

\begin{tabular}{|c|c|c|c|}
\hline & Odds Ratio & $\mathbf{P}>\mathbf{z}$ & 95\% Conf. Interval \\
\hline $\begin{array}{l}\text { Socio-demographics } \\
\text { Age }\end{array}$ & 0.93 & $<0.01$ & $0.92,0.95$ \\
\hline Male & 0.54 & $<0.01$ & $0.41,0.72$ \\
\hline African American & 1.14 & 0.44 & $0.82,1.59$ \\
\hline Other Race & 0.60 & 0.15 & $0.31,1.19$ \\
\hline Hispanic ethnicity & 1.28 & 0.41 & $0.72,2.27$ \\
\hline Nursing home residence & 0.45 & 0.12 & $0.17,1.23$ \\
\hline $\begin{array}{l}\text { Insurance coverage } \\
\text { Medicare insurance coverage }\end{array}$ & Reference & - & - \\
\hline Medicaid coverage & 0.90 & 0.74 & $0.47,1.69$ \\
\hline Dual eligibility & 1.35 & 0.39 & $0.68,2.70$ \\
\hline Private Insurance & 0.56 & $<0.01$ & $0.41,0.77$ \\
\hline No insurance & 1.97 & $<0.01$ & $1.21,3.22$ \\
\hline \multicolumn{4}{|l|}{ Functional limitations } \\
\hline \multicolumn{4}{|c|}{ Activities of Daily Living (ADLs) } \\
\hline No limitation & Reference & - & - \\
\hline 1 limitation & 1.62 & 0.02 & $1.08,2.44$ \\
\hline 2 limitations & 2.26 & $<0.01$ & $1.36,3.75$ \\
\hline 3 or more limitations & 2.35 & $<0.01$ & $1.41,3.91$ \\
\hline \multicolumn{4}{|c|}{ Instrumental Activities of Daily Living (IADL) } \\
\hline No limitation & Reference & - & - \\
\hline 1 limitation & 1.16 & 0.44 & $0.79,1.71$ \\
\hline 2 limitations & 1.13 & 0.65 & $0.66,1.96$ \\
\hline 3 or more limitations & 1.21 & 0.54 & $0.66,2.22$ \\
\hline \multicolumn{4}{|l|}{ Number of hospitalizations } \\
\hline No hospitalization & Reference & - & - \\
\hline 1 hospitalization & 1.42 & 0.04 & $1.02,1.97$ \\
\hline 2 hospitalizations & 1.63 & 0.02 & $1.09,2.43$ \\
\hline 3 or more hospitalizations & 2.02 & $<0.01$ & $1.35,3.02$ \\
\hline
\end{tabular}

Results from multivariate logistic regression analysis

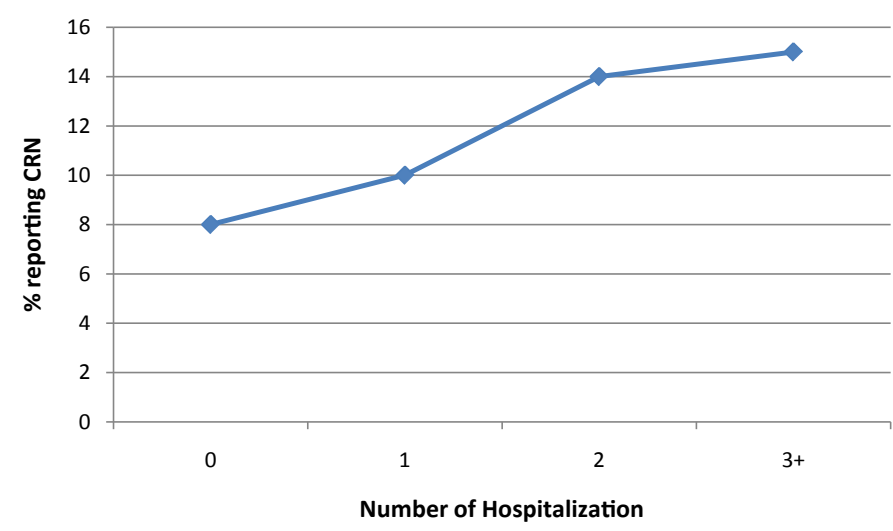

Figure 2. The association between the number of hospitalization and percentage of patients reporting CRN.

$\mathrm{p}<0.01$ by chi-square test. whether they had done so within the past 2 years.

Cancer is a costly medical condition and older cancer patients are often frail with many other conditions. While treatments are lifesaving and effective medications are available, the fact that patients with no insurance coverage reported higher CRN rates and sicker patients were more likely to report CRN suggested that the lack of adequate insurance coverage likely prevented them from receiving optimal health care. Together, these results suggest that expanding insurance coverage and improving insurance benefit design for cancer patients is likely to decrease CRN and improve outcomes. In addition, interventions that aim to reduce cost-cutting behaviors in these patients, such as generic medication substitution, have the potential of improving the effectiveness of treatment and reducing overall medical costs. Improving patient-physician communication on CRN may be instrumental in this process. 


\section{Acknowledgment}

The work is being supported in part by NIH K24 AG 031326 (Dr. Meltzer DO).

\section{References}

1. Gellad WF, Haas JS, Safran DG (2007) Race/ethnicity and nonadherence to prescription medications among seniors: results of a national study. J Gen Intern Med 22: 15721578. [Crossref]

2. Piette JD, Heisler M, Wagner TH (2004) Cost-related medication underuse among chronically ill adults: the treatments people forgo, how often, and who is at risk. $\mathrm{Am} \mathrm{J}$ Public Health 94: 1782-1787. [Crossref]

3. Steinman MA, Sands LP, Covinsky KE (2001) Self-restriction of medications due to cost in seniors without prescription coverage. J Gen Intern Med 16: 793-799. [Crossref]

4. Wilson IB, Rogers WH, Chang H, Safran DG (2005) Cost-related skipping of medications and other treatments among medicare beneficiaries between 1998 and 2000. J Gen Intern Med 20:715-720. [Crossref]

5. Soumerai SB, Pierre-Jacques M, Zhang F, et al. (2006) Cost-related medication nonadherence among elderly and disabled medicare beneficiaries: a national survey 1 year before the medicare drug benefit. ArchIntern Med 166:1829-1835. [Crossref]

6. Piette JD, Wagner TH, Potter MB, Schillinger D (2004) Health insurance status, costrelated medication underuse, and outcomes among diabetes patients in three systems of care. Med Care 42: 102-109. [Crossref]

7. American Cancer Society. Cancer Facts and Figures 2015. [http://www.cancer.org/ acs/groups/content/@editorial/documents/document/acspc-044552.pdf]. (accessed on October 10, 2015)

8. Dusetzina SB, Winn AN, Abel GA, Huskamp HA, Keating NL (2014) Cost sharing and adherence to tyrosine kinase inhibitors for patients with chronic myeloid leukemia. $J$ Clin Oncol 32: 306-311. [Crossref]

9. Nekhludov L, Madden J, Graves AJ, Zhang F, Soumerai SB, et al. (2011) Cost-related medication nonadherence and cost-saving strategies used by elderly Medicare cancer survivors. J Cancer Surviv 5: 395-404.

10. Lee M, Khan MM (2015) Gender differences in cost-related medication non-adherence among cancer survivors. J Cancer Surviv. [Crossref]

11. The Health and Retirement Study. Growing Older in America: The Health and Retirement Study. http://hrsonline.isr.umich.edu/index.php?p=dbook (accessed on October 10, 2015)

12. Zhang JX, Lee JU, Meltzer DO (2014) Risk factors for cost-related medication nonadherence among older patients with diabetes. World J Diabetes 5: 945-950. [Crossref]

13. Katz S, Ford AB, Moskowitz RW, Jackson BA, Jaffe MW (1963) Studies of illnes in the aged. the index of adl: a standardized measure of biological and psychosocial function. JAMA 185: 914-919. [Crossref]

14. Lawton MP, Brody EM (1969) Assessment of older people: self-maintaining and instrumental activities of daily living. Gerontologist 9: 179-186. [Crossref]

15. The Henry J. Kaiser Family Foundation. Concentration of health care spending in the U.S. population. [http://kff.org/health-costs/slide/concentration-of-health-carespending-in-the-u-s-population-2010/]. (accessed on October 11, 2015)

16. The Henry J. Kaiser Family Foundation. The Coverage Gap: Uninsured Poor Adults in States that Do Not Expand Medicaid - An Update. [http://kff.org/health-reform/issuebrief/the-coverage-gap-uninsured-poor-adults-in-states-that-do-not-expand-medicaidan-update/] (accessed on October 11, 2015)

17. ThunanderSundbom L, Bingefors K (2012) Women and men report different behaviours in, and reasons for medication non-adherence: a nationwide Swedish survey. Pharm Pract (Granada) 10: 207-221. [Crossref]

Copyright: (C) 2015 Zhang JX. This is an open-access article distributed under the terms of the Creative Commons Attribution License, which permits unrestricted use, distribution, and reproduction in any medium, provided the original author and source are credited. 